\title{
OPEN The impact of climate change in wheat and barley yields in the Iberian Peninsula
}

\author{
Virgílio A. Bento ${ }^{1 凶}$, Andreia F. S. Ribeiro ${ }^{1,2}$, Ana Russo ${ }^{1}$, Célia M. Gouveia ${ }^{1,3}$, \\ Rita M. Cardoso ${ }^{1}$ \& Pedro M. M. Soares ${ }^{1}$
}

The impact of climate change on wheat and barley yields in two regions of the Iberian Peninsula is here examined. Regression models are developed by using EURO-CORDEX regional climate model (RCM) simulations, forced by ERA-Interim, with monthly maximum and minimum air temperatures and monthly accumulated precipitation as predictors. Additionally, RCM simulations forced by different global climate models for the historical period (1972-2000) and mid-of-century (2042-2070; under the two emission scenarios RCP4.5 and RCP8.5) are analysed. Results point to different regional responses of wheat and barley. In the southernmost regions, results indicate that the main yield driver is spring maximum temperature, while further north a larger dependence on spring precipitation and early winter maximum temperature is observed. Climate change seems to induce severe yield losses in the southern region, mainly due to an increase in spring maximum temperature. On the contrary, a yield increase is projected in the northern regions, with the main driver being early winter warming that stimulates earlier growth. These results warn on the need to implement sustainable agriculture policies, and on the necessity of regional adaptation strategies.

Climate change and agriculture are fundamentally interconnected worldwide ${ }^{1-4}$. Indeed, the former has laid significant challenges to the agricultural sector in the last decades and is expected to further amplify these challenges in the near future ${ }^{5-7}$. On the other hand, agriculture is a major producer of greenhouse gas emissions to the atmosphere and thus partially responsible for causing climate change ${ }^{8,9}$. To overcome this cause/effect problem, policy reforms must be applied at the sector, national and international levels ${ }^{10}$. Examples are the implementation and correct execution of the Paris Agreement (COP21 Paris) by the countries' governments and the promotion of sustainable agriculture by reforming policies that stimulate unsustainable intensification and overuse of natural resources ${ }^{11-13}$. An additional burden related with intensive food production is that the world population is expected to significantly grow until the end of the century ${ }^{14}$, which creates adaptation problems concerning freshwater usage and food security ${ }^{15-17}$.

Wheat and barley are two of the major crops in the world used for food and drink production, being the nutritional basis for both humans and animals alike ${ }^{18}$. Hence, these crops are fundamental for global food security. Rainfed wheat and barley are key crops in the Iberian Peninsula, particularly in Spain (EUROSTAT, 2019), where their cultivation areas represent about $7 \%$ and $22 \%$, respectively, of the total EU-28 areas dedicated to these crops. Indeed, according to the EUROSTAT report for 2019, Spain is the country with the largest barley cultivation area in the EU-28; and is the 5th largest wheat cultivation area (following France, Germany, Poland, and Romania) in the EU-28.

The Mediterranean region, and in particular the Iberian Peninsula, has been identified as prominent climate change hot $\operatorname{spot}^{19,20}$. Nevertheless, climate change impacts and hence their consequences are not evenly distributed in space ${ }^{21}$, with their magnitude varying from region to region. With the aim of assessing this local to regional spatial variability, experiments to dynamically or statistically downscale Global Climate Models (GCMs) were designed within projects such as the Coordinated Regional Downscaling Experiment (CORDEX) ${ }^{22,23}$. As a result, a number of studies were developed resorting to these projects with the aim of analysing impacts of climate change on precipitation and temperature during the twenty-first century in regions encompassed within the Iberian Peninsula. These studies have consistently projected a decrease in the mean precipitation, and an increase in extreme precipitation events ${ }^{24-27}$. Furthermore, other studies ascertain a significant increase of both maximum and minimum temperatures in all seasons and climate change scenarios ${ }^{28,29}$.

${ }^{1}$ Instituto Dom Luiz, Faculdade de Ciências da Universidade de Lisboa, 1749-016 Lisbon, Portugal. ${ }^{2}$ Institute for Atmospheric and Climate Science, ETH Zurich, Universitätstrasse 16, 8092 Zurich, Switzerland. ${ }^{3}$ Instituto Português do Mar e da Atmosfera, I.P., 1749-077 Rua C do AeroportoLisbon, Portugal. ${ }^{\circledR}$ email: vabento@fc.ul.pt 
Multiple linear regression models are a relevant statistical tool used to model a given predictand by taking into account a set of key predictors ${ }^{30-32}$. These predictors may be selected by applying screening regression techniques, such as forward or backward stepwise regression analysis ${ }^{33}$. Such techniques have previously been employed to model past and future wine production from the Douro Valley in Portugal ${ }^{34}$, or to model wheat and barley yields in the Iberian Peninsula using drought indicators, such has the Standardized Precipitation-Evapotranspiration Index, and the remote sensing indices Vegetation Condition Index and Thermal Condition Index ${ }^{35}$. Additionally, several recent studies tackled the issue of wheat and barley yield fluctuations due to climate change, over different regions of the world ${ }^{36-42}$. Others, focused on the Iberian Peninsula, have studied the impacts of climate change on crop yields by using mechanistic crop growth models ${ }^{43-45}$, which require a high volume of input data, rigorous calibration, and often several in-situ observations ${ }^{46}$. Moreover, previous works for this region assessed the effects of projected maximum temperature extremes on cereal $\mathrm{crops}^{47}$, analysed the adaptation measures for managing wheat in a changing climate ${ }^{48}$, and studied how the diurnal temperature range and drought may affect wheat yields in the future ${ }^{49}$.

This work aims at expanding previous ones by assessing how climate change may affect both wheat and barley yields in the Iberian Peninsula. This is achieved by using a wide range of EURO-CORDEX RCMs simulated meteorological variables (such as maximum and minimum air temperatures and precipitation) representative of present and future climates, according to the Representative Concentration Pathways RCP4.5 and RCP8.5 greenhouse gas emission scenarios ${ }^{50}$. The relation between the meteorological constraining variables and wheat and barley yields is used to develop empirical models based on multiple linear regressions with the objective of projecting these yields in the future. Although the use of empirical relationships may not capture the biophysical aspects of crops, such models represent rather well the large-scale impacts of climate hazards and require lower computational costs than mechanistic modelling ${ }^{51,52}$. Hence, this work is divided in three main objectives:

(1) To establish a relation between wheat and barley yields and climate variables such as maximum $/ \mathrm{minimum}$ temperatures, and accumulated precipitation based on the CORDEX-Evaluation RCMs (forced with ERAInterim).

(2) To calibrate and validate regression models using predictors from the CORDEX-Evaluation RCMs, by comparing observed and modelled wheat and barley yields.

(3) To apply these regression models to CORDEX-Historical and CORDEX-Future RCMs, according to RCP4.5 and RCP8.5 scenarios, with the aim of studying and understanding future yield changes.

This work aims at assessing how wheat and barley yields may evolve if everything except climate remains unchanged. Ultimately, this study may be used as a helpful tool for decision-makers in the agriculture sector in the Iberian Peninsula, and hopefully it may warn on the need of implementing revised policies to immediately adapt and mitigate.

\section{Results}

Wheat and barley yield relation with temperature and precipitation. Two clusters in the Iberian Peninsula mainly composed by rainfed wheat and barley are selected to perform this study (Fig. 1). Correlations between observed wheat and barley yields and maximum air temperature (TX), minimum air temperature (TN), and accumulated precipitation (PR) simulated by the seven CORDEX-Evaluation RCMs show an overall good agreement (Fig. 2).

The case of PR is the most striking, showing a large consistency among RCMs for wheat and barley over the two clusters. Moreover, the dependence of cereal yields on climatic variables reveals a contrasting behaviour between the two clusters. In cluster 1, positive anomalies of precipitation in April and May are the most important contributors to wheat and barley yield, while positive (negative) precipitation anomalies in March embody a negative (positive) effect in these yields. In cluster 2, positive anomalies of precipitation in April and May provide an important contribution to the productivity of the two cereals, albeit with a decrease in relevance of May precipitation when compared to cluster 1. Furthermore, winter precipitation proves to be an important factor to harvested yield, with November (wheat and barley) and December (wheat) showing large positive correlations.

On the other hand, TX and TN correlations with observed wheat and barley yields show larger variations dependent on the selected RCM. These are most prominent over cluster 1 (northern), where TX and TN show contrasting correlations in April and May, depending on the chosen RCM. The most notable differences are between IPSL-WRF381P TX and TN (correlations of about -0.1 and 0.4 ) and CNMR-ALADIN63 TX and TN (correlations of about -0.6 and -0.3 ) with both cereal yields. Due to inter-RCM differences, it is not as simple to define the most important yield-driving factors as with PR. In general, in cluster 1, warm (cold) winters and mild (warm) springs are the most favourable (unfavourable) to wheat and barley growth. While for the case of TN, the most consistently important month among RCMs is March, where mild (warm) minimum temperatures have a positive (negative) contribution to cereal yield. In cluster 2, TX in April and May, and TN in May show a large relation with both wheat and barley yields (with correlations up to -0.8). Thus, for each cluster and cereal a stepwise regression method is applied to select the most relevant predictors for the various CORDEXEvaluation RCMs.

Development of regression models. Selected predictors-one set of predictors for each CORDEXEvaluation RCM - to forecast wheat and barley yields over the two clusters are shown in Fig. 3. Different shades of blue indicate the linear regression coefficient relative weight, and the symbols ' + ' and '-' indicate a positive or negative coefficient, respectively. As an example, let us consider the predictors that are selected to forecast wheat yield over cluster 1 with CCLM5-8-17 model (evaluation): TX11, TX05, and PR04 (November and May TX, 
Cluster 1

1. Burgos

2. Palencia

3. Segóvia

4. Valladolid

5. Zamora

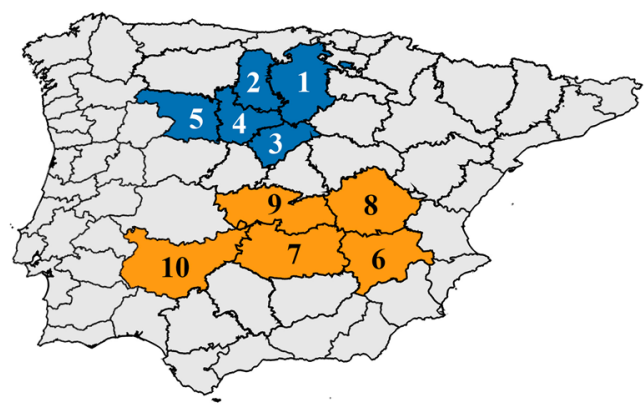

6. Albacete

7. Ciudade Real

8. Cuenca

9. Toledo

10. Badajoz
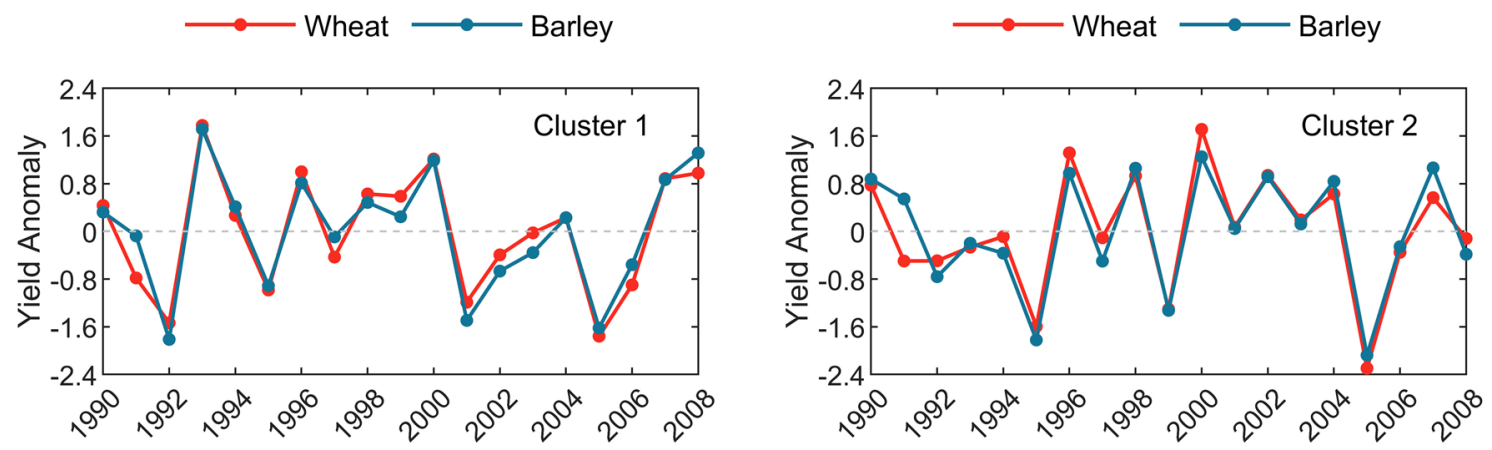

Figure 1. (top) Map with provinces that encompass cluster 1 (blue) and cluster 2 (orange); (bottom) Standardized detrended yield anomaly $(\mu=0, \sigma=1)$ of wheat (red) and barley (blue) for cluster 1 (left panel) and cluster 2 (right panel).

and April PR). The linear regression model may be written as $Y_{\text {wheat }}=a_{1} T X 11-a_{2} T X 05+a_{3} P R 04$, where $a_{1}, a_{2}, a_{3}$ are the regression coefficients, having relative weights of $27 \%, 30 \%$, and $43 \%$, respectively, for the exemplified case.

Although different sets of predictors are selected for each combination of RCM/cluster/cereal, some general patterns are found. For cluster 1, the most relevant predictors are PR04 (for 6 out of 7 RCMs, both cereals) and PR05 ( 3 out of 7 RCMs, both cereals), which is in agreement with Fig. 2.

In the case of cluster 2, wheat and barley predictors are not similar, with TX04 (5 out of 7 RCMs) and PR04 (5 out of 7 RCMs) selected to forecast wheat, whilst TX04 (6 out of 7 RCMs) and TN04 (5 out of 7 RCMs) are selected for barley. Furthermore, precipitation in winter seems to have some degree of importance in forecasting wheat (5 out of 7 RCMs selected: November (2), December (2), and January (3)), which is on par with results from Fig. 2.

In general, linear regressions are characterized by $2-5$ predictors, depending on the RCM. The exception is DMI-HIRHAM5, which regression is composed of 7 predictors. However, tests show no conspicuous overfitting. Moreover, correlations after cross-validation range between 0.59 (explaining $18 \%$ of the variance) and 0.97 (explaining $92 \%$ of the variance). Notably, cluster 2 shows smaller differences (MAE ranging from 0.19 to 0.55 ) between observed and forecasted yields than cluster 1 (MAE ranging from 0.39 to 0.67 ).

Comparison between wheat and barley observed and forecasted yields with CORDEX-Evaluation RCM distributions are displayed in Fig. 4 as ECDFs and box plots. After comparing each RCM-derived yield with the observed yield with a two sample Kolmogorov-Smirnov test, the null hypothesis that both samples come from the same distribution is verified, at 5\% significance level, for all RCM-derived yields and for the multi-model ensemble. Nevertheless, box plots show the inherent variability among models, notably for wheat in cluster 1 .

Application of the regression models to predict future wheat and barley yields. Coefficients derived from the Evaluation runs are applied to the GCM forced RCMs for the historical (1972-2000) and midof-century (2042-2070) climates (see Supplementary Figure S1 for end-of-century 2071-2100). Figure 5 shows the yield production ECDFs from the multi-model ensemble. Results are similar between cereals, but show different behaviour depending on the cluster. Moreover, Kolmogorov-Smirnov test rejects the null hypothesis that the future (in both RCPs) and historical samples are from the same continuous distribution at 5\% significance level.

Over cluster 1, both wheat and barley mid-of-century distributions are similar to the historical yields for negative anomalies, albeit fewer extreme losses are projected. In contrast, positive anomalies in the future differ significantly from the ones estimated for the historical climate, with a propensity to larger positive extremes. Indeed, there is a shift to the right of the ECDFs representing the mid-of-century, which becomes larger with greater yield. With increasing warming, the yield distribution for mid-of-century RCP 8.5 shows the largest shift to the right. As an example, wheat yield anomalies larger than 2 have a probability of occurrence of near $0 \%$ in the historical period; whereas in the RCP 8.5 future climate, this probability increases to about $13 \%$. On the positive 
Wheat

Cluster 1
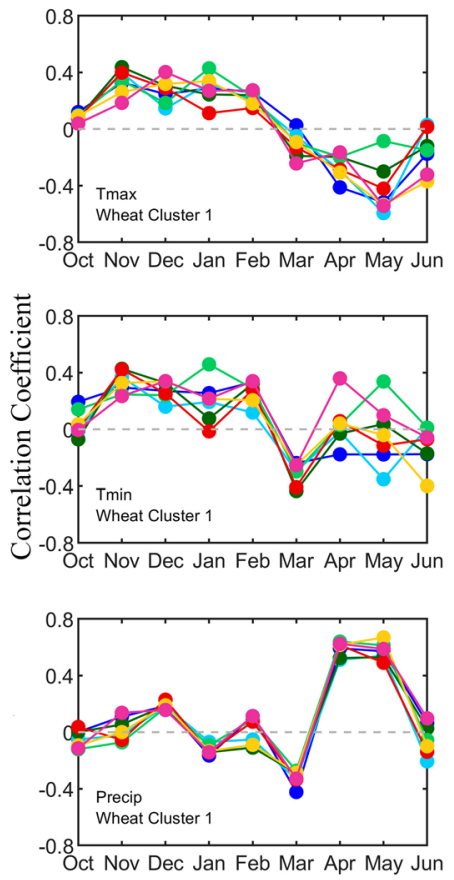

Cluster 2
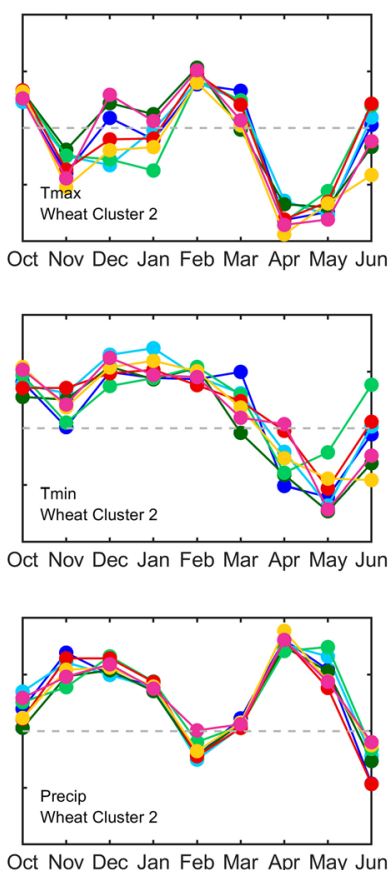

Oct Nov Dec Jan Feb Mar Apr May Jun
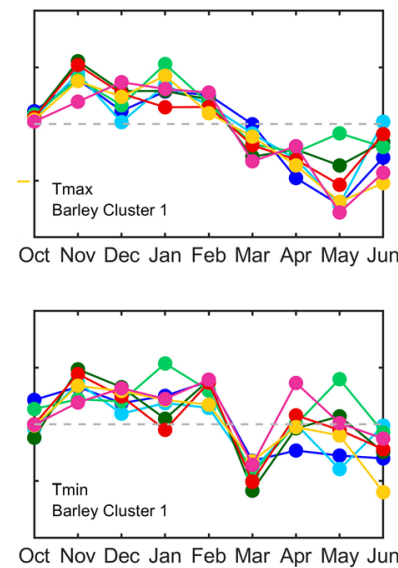

Oct Nov Dec Jan Feb Mar Apr May Jun

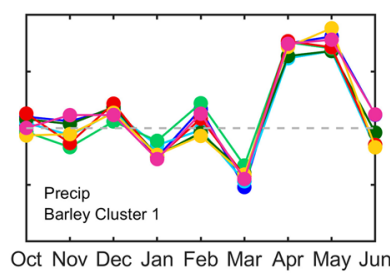

Oct Nov Dec Jan Feb Mar Apr May Jun
Barley

Cluster 2
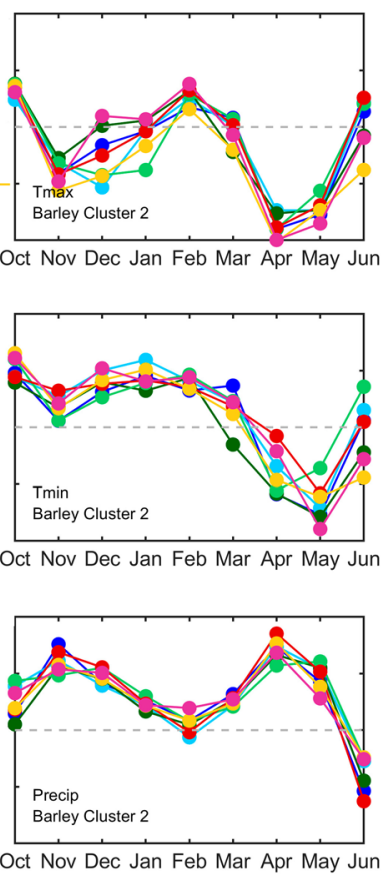
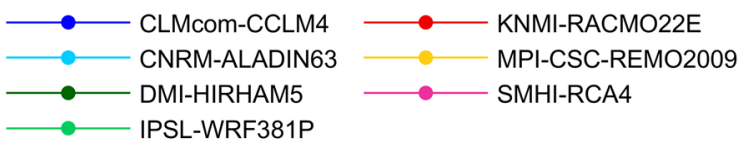

Figure 2. Correlation between standardized detrended yield anomaly of wheat (left panels) and barley (right panels) and CORDEX-Evaluation models standardized detrended precipitation (bottom), Tmax (top), and Tmin (middle) for cluster 1 and cluster 2.

extreme of the wheat yield ECDFs spectrum, historical period never displays anomalies larger than circa 3.5, whereas in the mid-of-century these anomalies may surpass 6.

Cluster 2 shows rather different results than those of cluster 1. Here, for both cereals the analysis reveals a shift to the left of the ECDFs representative of the mid-of-century period; i.e., higher probabilities of having yield losses, independently of the anomaly sign. Differences between historical and mid-of-century are more severe than in cluster 1 . Indeed, the probability of having barley yield anomaly lower than -2 in the historical climate amounts to about $4 \%$ and anomalies smaller than -4 are never identified; in the RCP8.5 (RCP4.5) future climate the probability of having barley yield anomalies lower than -2 reaches more than $30 \%$ (18\%), and anomaly losses may exceed -7. Notwithstanding, such remarkable shift to the left is not found for positive anomalies, particularly on the extreme end of the ECDFs, where wheat gains remain somewhat similar between historical and mid-of-century climates, and barley anomalies show a decrease from 3 (historical) to 1.8 and 2.2 (RCP8.5 and RCP4.5, respectively).

An additional feature shown by the distributions displayed in Fig. 5 is the propensity for wheat yields to undergo larger future increases than barley yields, over cluster 1; and for barley yields to endure larger future losses than wheat, over cluster 2.

\section{Discussion}

Correlations between climate variables and wheat and barley yields show a very good agreement among RCMs, particularly in terms of precipitation. Here, the growing season cycles show very distinguishable patterns which are in agreement with results presented in another study ${ }^{53}$, stating that a good production year is influenced by precipitation (more pronounced in cluster 2) and warm temperatures (above average in the more temperate north cluster 1, and below average in the drier cluster 2) in late autumn and early winter, which is paramount to prepare the soil to catch-crop. Moderate amounts of precipitation in early spring, more precipitation and below average temperatures in April and May, and a warm and dry June allow for a slow and complete maturation originating filled and well-formed grains ${ }^{53,54}$.

The signal of climate change in agreement with the two scenarios for the mid-of-century key selected predictors is illustrated in Fig. 6 (the expanded results with end-of-century are shown in Supplementary Figure S2). 


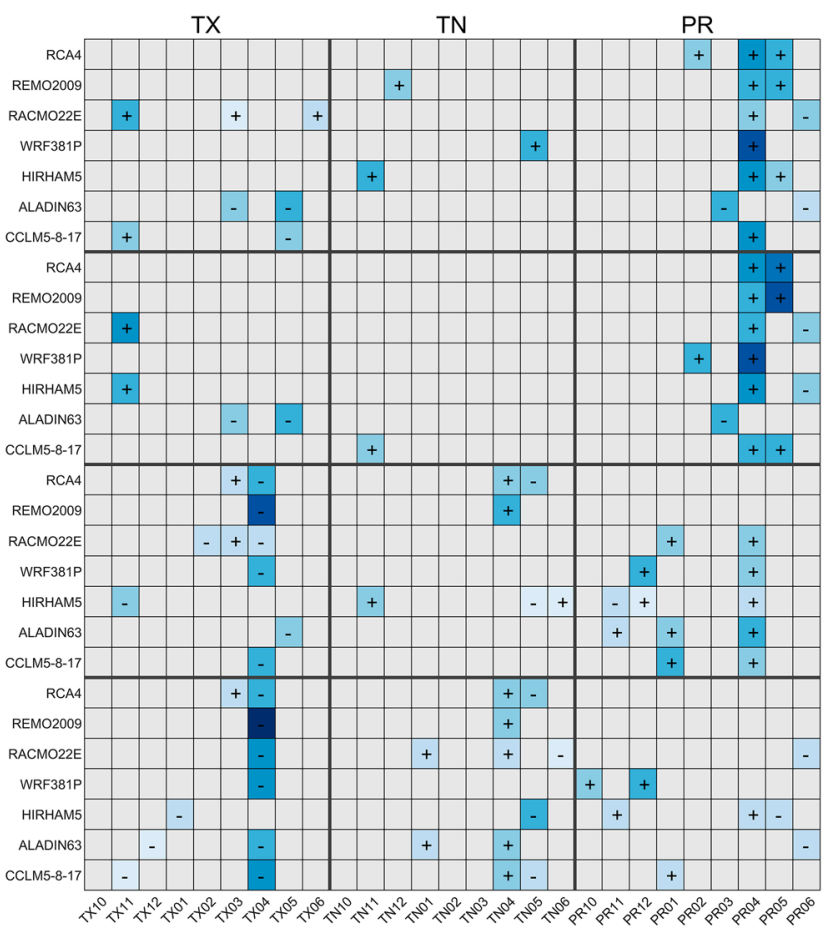

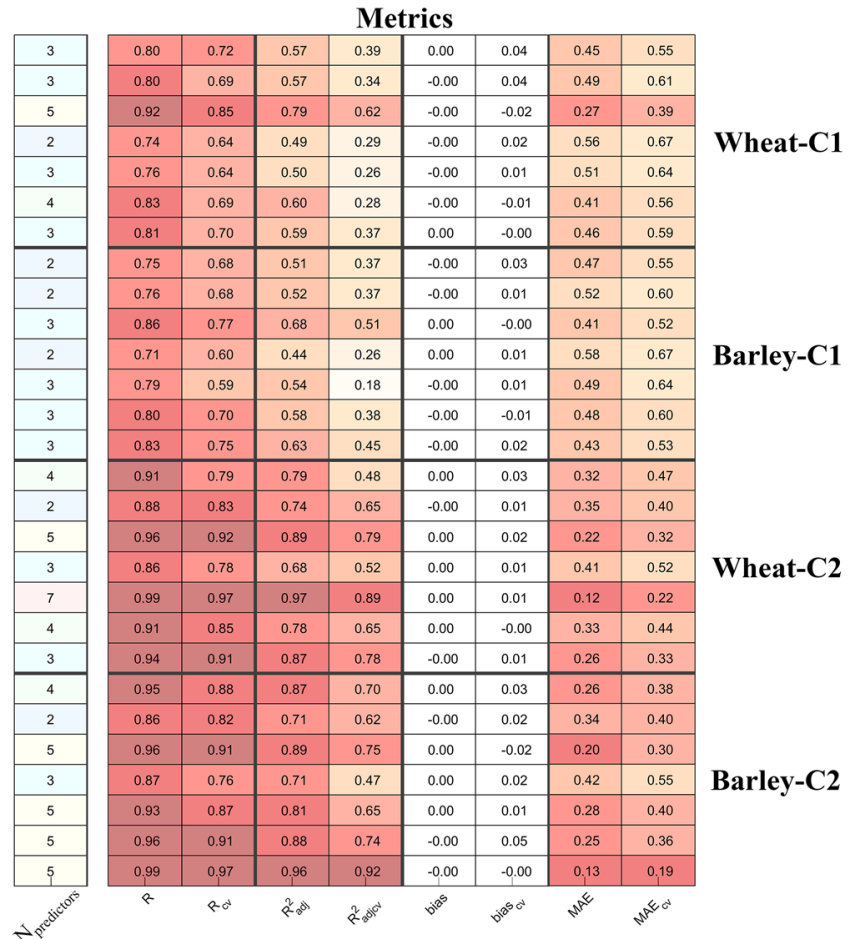

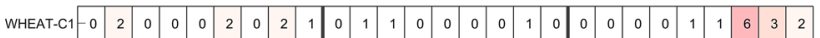
\begin{tabular}{c|c|c|ccccccccccccccccccccccccc} 
BARLEYCC1 & 0 & 2 & 0 & 0 & 0 & 1 & 0 & 1 & 0 & 0 & 1 & 0 & 0 & 0 & 0 & 0 & 0 & 0 & 0 & 0 & 0 & 0 & 1 & 1 & 6 & 3 & 2 \\
\hline
\end{tabular} \begin{tabular}{llllllllllllllllllllllllllllllll|} 
WHEAT-C2 & 0 & 1 & 0 & 0 & 1 & 2 & 5 & 1 & 0 & 0 & 1 & 0 & 0 & 0 & 0 & 2 & 2 & 1 & 0 & 2 & 2 & 3 & 0 & 0 & 5 & 0 & 0 \\
\hline
\end{tabular}

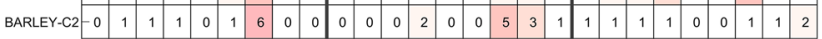

Number of times a predictor is selected

Figure 3. Representation of the selected predictors (displayed in tones of blue) for each CORDEX-Evaluation RCM. The matrix is divided into 9 blocks corresponding to TX, TN, and PR predictors from October to June (left to right), and the 7 RCMs for wheat and barley in cluster 1, and wheat and barley in cluster 2 (top to bottom). Tones of blue indicate the relative percentage of the coefficient associated to a given predictor and sum to $100 \%$ for each RCM. Symbols '+' and '-' specify if the coefficient is positive or negative, respectively. The bottom table shows the number of times a predictor is selected by cereal and cluster. The single column table at the right of the matrix indicate the number of predictors by RCM, cereal, and cluster. The table on the right displays the metrics associated to the comparison between cereal yields observed and predicted with regression models before and after cross-validation (cv): correlation $\mathrm{R}, R_{\text {ajd }}^{2}$, bias, and MAE, in order from left to right.

These consist of TX in November, March, April, and May; TN in April and May; as well as PR in January, April, May, and June.

In cluster 1, wheat and barley yields are mainly driven by spring precipitation (April and May) with positive coefficient sign. These predictors are expected to have slightly negative anomalies in the future. This would ultimately result in a decrease of cereal yields. However, results show the opposite, with larger yield increases in the mid-of-century. Indeed, other predictors may contribute with an opposite effect, such as TX in November, which is a used predictor in CCLM5-8-17 and RACMO22E for wheat (accounting for circa 40\% of the RCMs used), and HIRHAM5 and RACMO22E for barley (almost 35\% of the RCMs). Furthermore, changes in TX11 are substantial with respect to those expected in precipitation predictors, which also helps explain such increases in mid-of-century cereal yields.

In cluster 2, spring maximum temperature is the main yield driver (negative coefficients, positive anomalies), which leads to a decrease in both wheat and barley yields in the future.

Indeed, climate change may negatively affect wheat and barley crops situated in regions where temperatures and precipitation are already ideal to its development, where a small change may largely disturb growing mechanisms $s^{55}$. On the other hand, the expected warming of colder regions, here exemplified by the northern cluster 1, may have a beneficial outcome in wheat and barley growth, particularly in early winter where higher temperatures may bolster cereal development ${ }^{56,57}$. Furthermore, a comparison between several process-based crop models was previously analysed for barley in the region of Lleida, in the northeaster Spain ${ }^{58}$. In that study, the authors tested the response of crop growth and yield to several perturbed variables, such as temperature, precipitation, solar radiation, and $\mathrm{CO}_{2}$. Results showed increased barley yields with an increase in temperature, 
Wheat

Cluster 1
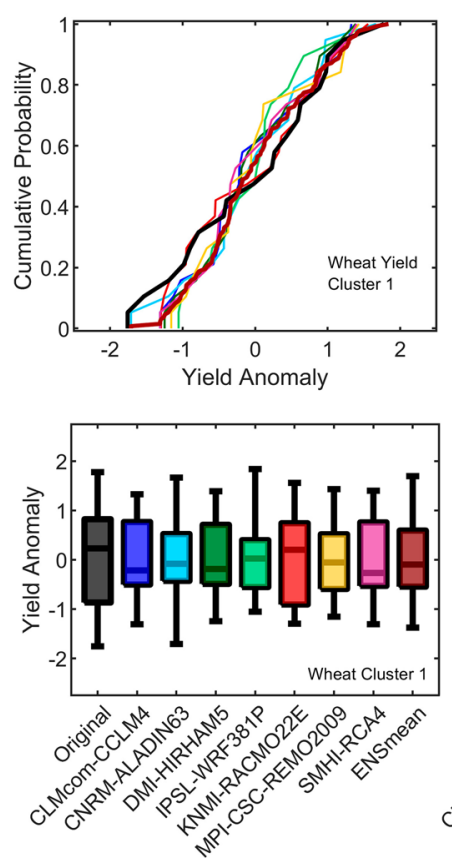

Cluster 2
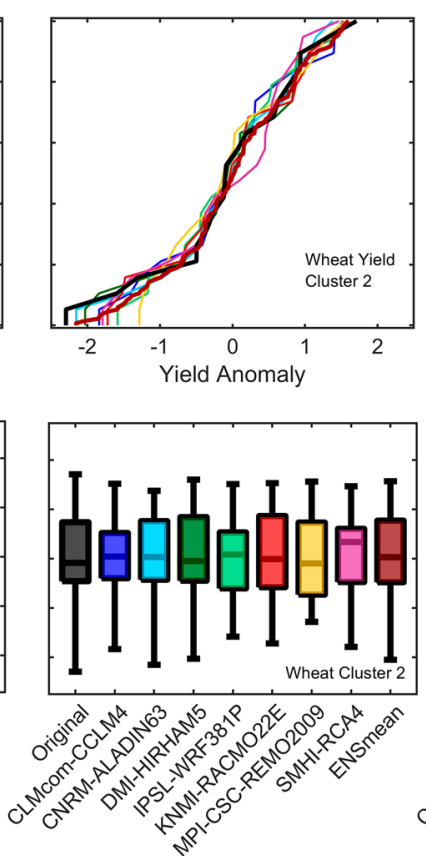

Barley

Cluster 1
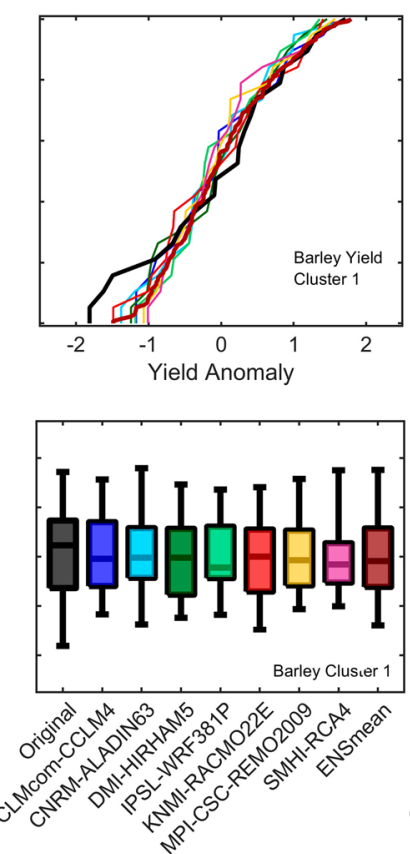

Cluster 2
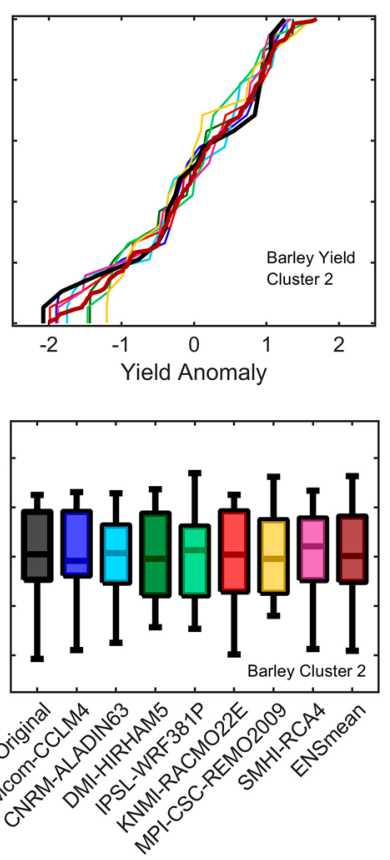

Figure 4. Comparison between distributions of yield anomaly in the form of ECDFs (top) and boxplots (bottom) for the 7 CORDEX-Evaluation models, the multi-model ensemble yield mean, and the observed values. Boxes range from the 25 th to the 75 th percentiles with the median depicted inside the box; whiskers represent the 1st and 99th percentiles.

precipitation, and $\mathrm{CO}_{2}$ since a milder winter can be beneficial for the winter barley cultivated there. Such results agree with those presented here for the northern cluster 1 . As expected, changes associated with the RCP4.5 scenario are characterized by the same signal and features as RCP8.5, but with smaller magnitudes.

These results focus on heat stress and water deficits at monthly scale, and do not directly account for larger scale extreme climatic events, such as droughts. In fact, droughts may largely contribute to yield variability, particularly in Spain ${ }^{56}$. Indeed, high temperatures are a key driver to increase the vapor pressure deficit (VPD) on the atmosphere and thus the evaporative demand, which in turn contributes to water stress. Hence, drought episodes may exacerbate this process by increasing the water stress ${ }^{59,60}$.

Results from previous studies ${ }^{42,49}$, focusing on the effects of drought, diurnal temperature range, and surface solar radiation to predict the expected range of projected wheat yield trends until the end of the twenty-first century in Spain, agree with those presented here, indicating downward trends in wheat production. Another study ${ }^{47}$ focused on the impact of maximum temperature in maize and spring wheat crops, concluded that southern and northern Spain show dichotomous behaviour, with the southern region being more affected by a decrease in maize yield due to climate change. The projected larger decreases in barley yield when compared with wheat yield concur to the premise that barley is the most vulnerable crop to climate extremes over the provincial clusters analysed in this study which is in accordance with previous studies on that area ${ }^{61,62}$. However, this is still a matter of debate among previous works over the Mediterranean areas ${ }^{63-66}$, and the overperformance of wheat or barley under lowest-yielding conditions is not clear. Nevertheless, few studies have analysed how extreme impacts on both wheat and barley yields are changing under global warming at the sub-national level under rainfed conditions. Other approaches such as the Combined Stress Index (CSI ${ }^{67}$, which combines Heat Magnitude Day (HMD; dependent on maximum daily temperature) and the Standardized Precipitation-Evapotranspiration Index (SPEI) were used at the country level to estimate climate resilience and anomalies effect on wheat ${ }^{68}$ and maize ${ }^{69}$ in future scenarios of climate change. The CSI has the advantage of depending on non-parametric indicators, i.e., impartial to biases inherent to climate data.

It is important to note that results shown here assume that current wheat and barley genotypes, vernalization, irrigation (or lack thereof), sowing dates, and other management techniques ${ }^{70}$ remain unchanged in the future. Naturally, changes in these factors may be considered adaptation strategies to climate change, which are in continuous development as the impacts and consequences of climate change are more notorious ${ }^{71-77}$. Results presented here assume a scenario of no-adaptation, and thus represent the worst-case hypothesis, which may be softened by adaptation policies. For example, rainfed winter wheat is a difficult crop to implement adaptation measures, being nevertheless possible to effectively adapt by applying a combination of techniques, such as early sowing dates ${ }^{48}$. This may be a viable strategy to overcome climate change impacts in wheat production for the southern cluster, allowing the crop to develop during a cooler period of the year, which may partially avoid water stressed periods ${ }^{78-80}$. Other strategies like double-cropping ${ }^{81,82}$, breeding ${ }^{83}$, adapted crop varieties ${ }^{84}$ may 

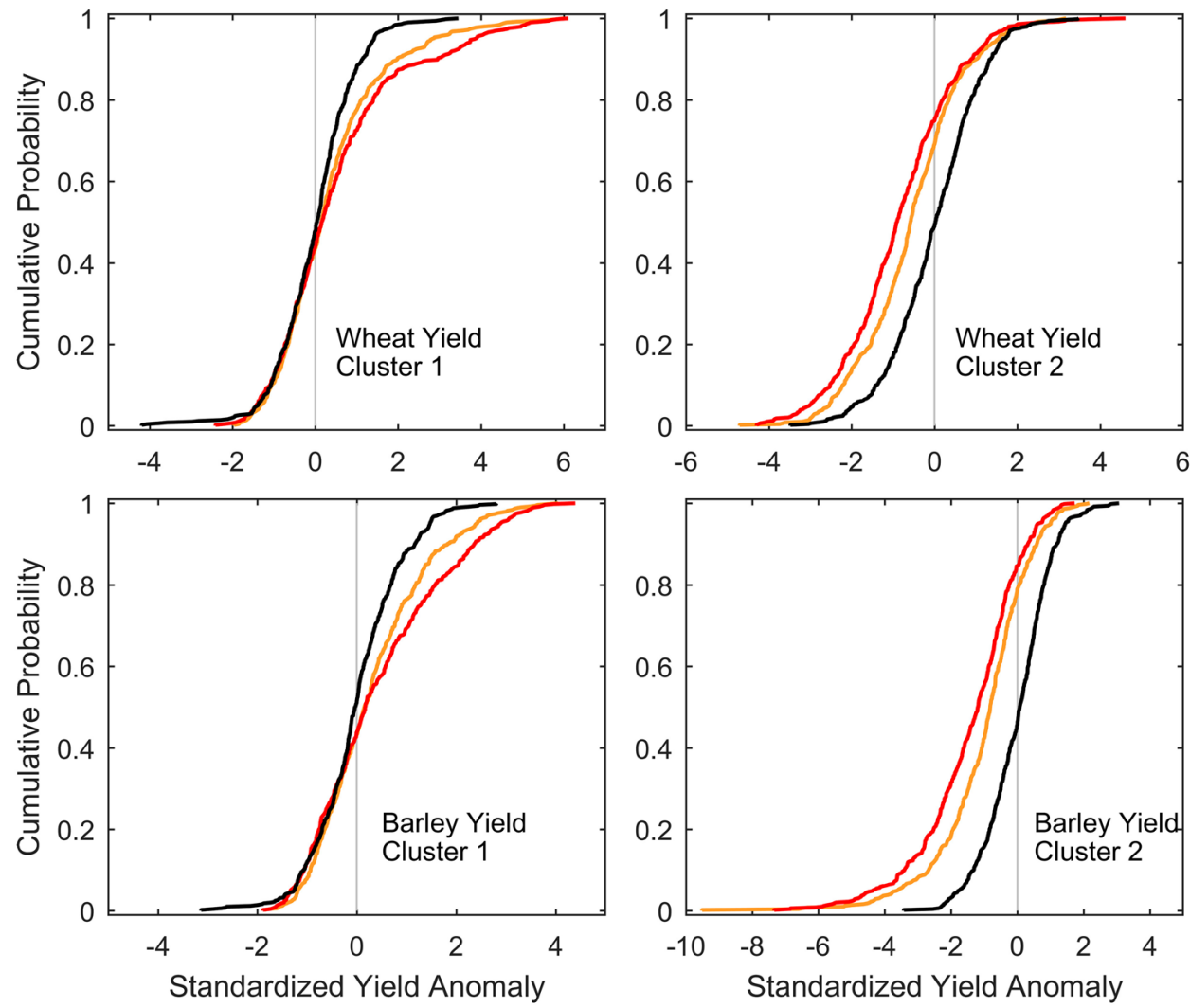

Figure 5. Pooled wheat (top) and barley (bottom) yield anomalies using RCP4.5 (orange) and RCP8.5 (red) for the 2042-2070 period in relation to the historical (1972-2000; black line). Yield was estimated using regression coefficients for individual GCM/RCM models.

also be applied to mitigate climate change impacts on wheat yields in that region. Conversely, the northward shift of suitable area should make the northern cluster more apt for wheat production, without changing sowing dates ${ }^{78}$. Moreover, it is relevant to stress that projections of wheat and barley yields to the mid-of-century period entail uncertainties due to multiple interrelated biophysical processes ${ }^{58}$. The use of multi-model ensembles should be seen as a tool to reduce these uncertainties. Indeed, the high degree of coincidence between the different GCM-RCM variables implies a robust result. Nevertheless, uncertainties that may arise from model structure and parametrizations of process-based crop models ${ }^{85}$ are not addressed in this work. This is because empirical models do not incorporate a detailed formulation of the physical processes that drive crop and climate relations, aiming only at representing large scale impacts of climate in yields, typically showing similar results to process-based models ${ }^{52,86}$.

This study shows that climate change may have a severe impact on the agricultural landscape as defined today. Indeed, the Iberian Peninsula is notorious for being both a major hot spot for climate change and a major region for rainfed wheat and barley cultivation. However, future changes in cereal production do not show a homogeneous behaviour along the peninsulas' major farming regions. Indeed, there seems to be a dichotomous demeanour between wheat and barley outputs depending on the latitude they are planted. Severe yield losses are projected for both cereals in the southern region mainly due to the increase in maximum temperatures in spring, particularly when assuming the worst-case scenario of greenhouse gas concentration trajectory. On the other hand, wheat and barley situated further north in the Iberian Peninsula show an increase in yield, which may be linked with the warming of early winter months. This agrees with the observed northward shift of agro-climatic zones and the consequent transition of crop growth suitability ${ }^{87}$. These results show that, as it stands, wheat and barley agriculture may no longer be a viable source of food and income to farmers and to the population in general in southern regions of the Iberian Peninsula, which today largely depends on the social and economic benefits of sowing these cereals. Indeed, this study aims at exposing the influence of climate change (impacts in temperature and precipitation) in the future of these crops, and to alert for the need to implement changes, whether these are local (changing the cultivar species of wheat and barley), country wise (implementing sustainable policies that help mitigate climate change impacts), or even global (mitigate greenhouse gas emissions altogether). 

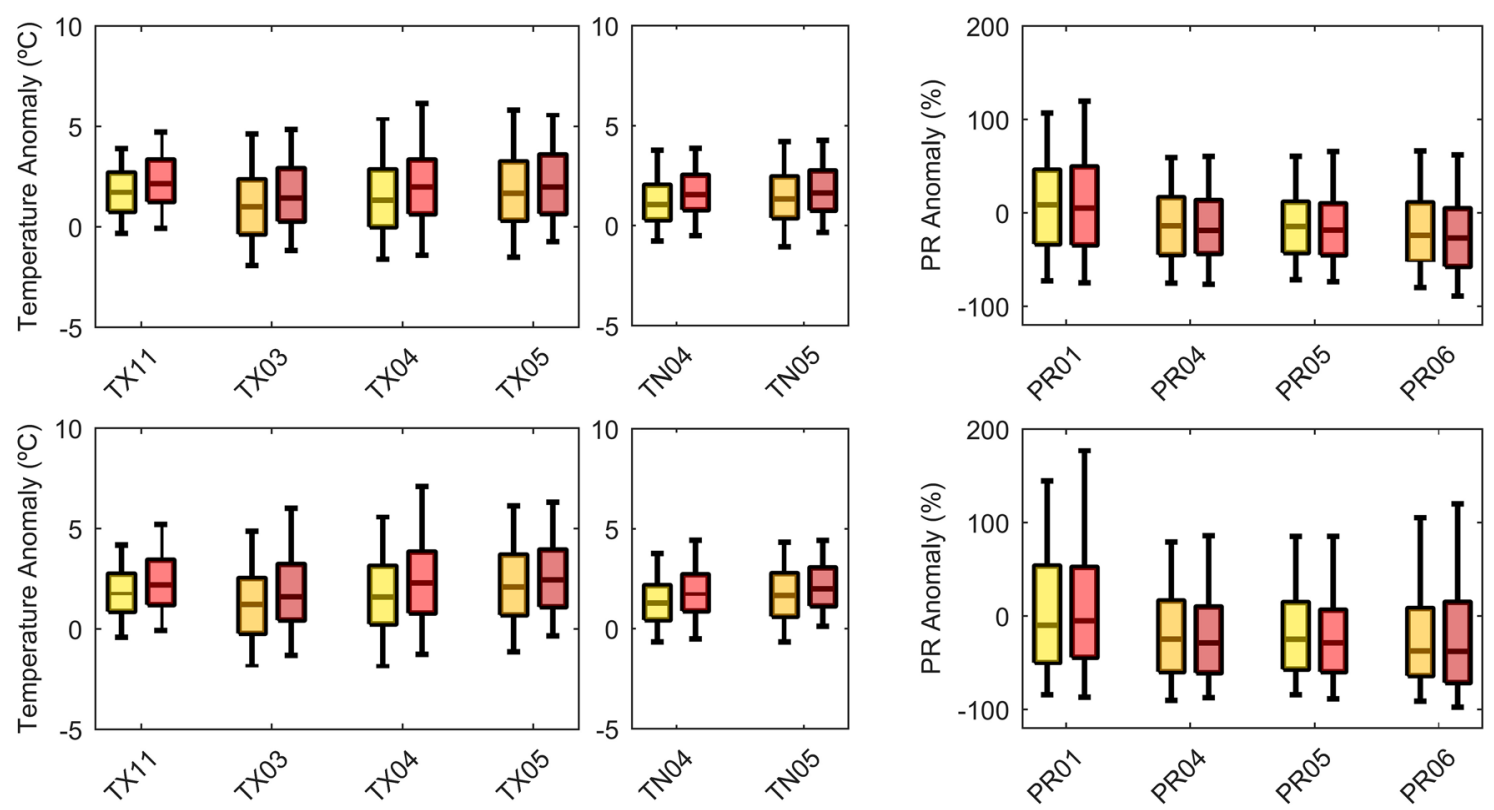

Figure 6. Distribution of TX $\left({ }^{\circ} \mathrm{C}\right), \mathrm{TN}\left({ }^{\circ} \mathrm{C}\right)$ and $\mathrm{PR}(\%)$ anomalies (future-historical) for the most relevant predictors (TX11, TX03, TX04 and TX05; TN04 and TN05; PR01, PR04, PR05 and PR06) for cluster 1 (top) and cluster 2 (bottom). Each boxplot represents the combined distribution of the CORDEX available models for the: (yellow) RCP4.5 2042-2070; (orange) RCP8.5 2042-2070.

\section{Methods}

Among the Iberian Peninsula provinces with larger percentages of agricultural land-use and dominated by rainfed cropping systems, we selected two clusters for analysis, comprising 10 provinces in Spain. Figure 1 shows the spatial distribution of the provinces which were aggregated in two regionally distinct clusters, each one consisting of 5 neighbouring provinces. The selection criteria of the study area were built on prior works conducted by the authors ${ }^{35,61}$, to which we added the province of Badajoz that has a slightly lower percentage of rainfed area, but similar climate conditions (in terms of precipitation and temperature), allowing therefore to consider the same sample size in each cluster, and hence, making easier an accurate regional comparison between the two clusters.

For the selected provinces, annual yield anomalies ( $\mathrm{t} / \mathrm{ha}$ ) of wheat and barley were obtained based on area (ha) and ton of production ( $\mathrm{t}$ ) from the Spanish Agriculture, Food and Environment Ministry (available at https:// www.mapa.gob.es). Spatial averages were computed for each cluster and long-term trends were removed by linear detrending, in order to exclude non-climatic factors such as technological development ${ }^{88}$. The time-series were further standardized (Fig. 1, bottom panel).

Precipitation (PR) and daily maximum and minimum temperatures (TX and TN) for the Iberian Peninsula, were retrieved from the EURO-CORDEX $0.11^{\circ}$ resolution simulations (Table 1) in the Earth System Grid Federation (ESG) portal. Seven of the 1989 to 2008 ERA-Interim ${ }^{89}$ forced simulations (Evaluation) were used for an initial RCM assessment and the establishment of the regression model predictors. From the 130-year climate projections $^{26}$, 19 GCM-RCM combination results were selected, for the historical period (1971-2000) and two future periods (2041-2070 and 2071-2100), in agreement with the two representative concentration pathways, RCP4.5 and RCP8. $5^{50}$. All simulations were performed on a common European domain and grid.

In order to study the relationship between the two clusters' annual production of wheat and barley, and the growing season cycles of TX, TN, and PR, the Pearson's linear correlation coefficient is estimated for each of the seven CORDEX-Evaluation RCMs.

With the aim of predicting wheat and barley production, a stepwise regression is then applied to select sets of statistically significant predictors for linear regression models (the pool of potential predictors consists of monthly TX, TN, and PR from October to June). A total of 28 regression models are developed, representing the seven CORDEX-Evaluation RCMs, two geographic clusters, and two cereals. Overfitting is precluded by using a leave-one-out cross validation scheme $\mathrm{e}^{33}$. The fitting procedure is repeated by sequentially leaving one observation and the respective predictor(s) out of the training data, and then applying the resulting regression model to the left-out validation data. This approach is repeated by the number of observations that comprise the time-series (19 in this case, representing a given month spanning the 19 years that compose the evaluated period of ERA-Interim forced CORDEX RCMs). The predicted and observed wheat and barley yields with and without cross-validation are subsequently compared using the following metrics: (i) Pearson's linear correlation coefficient $\mathrm{R}$, (ii) the $\mathrm{R}^{2}$ adjusted to the number of predictors in the regression model $\mathrm{R}_{\text {adj; }}^{2}$ (iii) the bias, and (iv) the Mean Absolute Error (MAE). Distributions of predicted and observed wheat and barley yields are displayed as Empirical Cumulative Distribution Functions (ECDFs) and box plots. A two sample Kolmogorov-Smirnov 


\begin{tabular}{|c|c|c|c|}
\hline Forcing & RCM & Institute & References \\
\hline ERA-interim & \multirow{5}{*}{ CCLM4-8-17 } & \multirow{5}{*}{ CLM } & \multirow{5}{*}{ Rockel et al..$^{90}$} \\
\hline CNRM-CM5 & & & \\
\hline EC-Earth & & & \\
\hline HadGem2-ES* & & & \\
\hline MPI-ESM-LR & & & \\
\hline ERA-interim & \multirow{2}{*}{ ALADIN63 } & \multirow{2}{*}{ CNRM } & \multirow{2}{*}{ Nabat et al. ${ }^{91}$} \\
\hline CNRM-CM5 & & & \\
\hline ERA-interim & \multirow{4}{*}{ HIRHAM5 } & \multirow{4}{*}{ DMI } & \multirow{4}{*}{ Christensen et al..$^{92}$} \\
\hline EC-Earth & & & \\
\hline HadGem2-ES* & & & \\
\hline NorESM1-M & & & \\
\hline ERA-interim & \multirow{2}{*}{ WRF381P } & \multirow{2}{*}{ IPSL } & \multirow{2}{*}{ Skamarock et al. ${ }^{93}$} \\
\hline IPSL-CM5A-MR & & & \\
\hline ERA-interim & \multirow{4}{*}{ RACMO22E } & \multirow{4}{*}{ KNMI } & \multirow{4}{*}{ Van Meijgaard et al..$^{94}$} \\
\hline CNRM-CM5 & & & \\
\hline EC-Earth & & & \\
\hline HadGem2-ES* & & & \\
\hline ERA-interim & \multirow{2}{*}{ REMO2009 } & \multirow{2}{*}{ MPI } & \multirow{2}{*}{ Jacob et al. ${ }^{95}$} \\
\hline MPI-ESM-LR & & & \\
\hline ERA-interim & \multirow{7}{*}{ RCA4 } & \multirow{7}{*}{ SMHI } & \multirow{7}{*}{ Samuelsson et al. ${ }^{96}$} \\
\hline CNRM-CM5 & & & \\
\hline EC-Earth & & & \\
\hline IPSL-CM5A-MR & & & \\
\hline HadGem2-ES* & & & \\
\hline MPI-ESM-LR & & & \\
\hline${ }^{\star}$ End-of-century 2072-2098 & & & \\
\hline
\end{tabular}

Table 1. CORDEX regional climate models (RCMs) used in this study, along with the forcing and the institute responsible. Forcings are of two types: (i) ERA-Interim, which represents CORDEX-Evaluation RCMs spanning the period between 1989 and 2008; and (ii) global climate models (GCMs) representing both CORDEX-Historical and CORDEX-Future RCMs. The former describes the present climate (1971-2000), while the latter takes advantage of RCP4.5 and RCP8.5 to describe different future climates. ${ }^{*}$ End-of-century 2072 - 2098.

test is used to test the null hypothesis that predicted and observed yields come from the same distribution, at $5 \%$ significance level.

For each RCM, the resulting regression model is then applied to estimate wheat and barley yields using the predictors from the respective CORDEX-Historical and CORDEX-Future RCM simulations. Projections of wheat and barley yields for future climates are computed for RCP 4.5 and RCP 8.5 scenarios. Since CORDEX GCM-RCM combinations are numerous, a multi-model ensemble is established by pooling the resulting cereal production yields, i.e., reshaping the 29 -year by 18 CORDEX GCM-RCM models' yield time-series in a onedimensional sample consisting of 522 forecasted values. ECDFs representative of these pooled yields are further displayed with the objective of identifying potential changes in future wheat and barley production relative to the historical period. To assess if yields derived from CORDEX-Historical and CORDEX-Future are statistically dissimilar, (5\% significance level) the nonparametric two-sample Kolmogorov-Smirnov test is used.

To understand the major drivers of yield changing in future climates, anomalies of TX, TN and PR are computed. These are estimated for CORDEX RCMs forced with GCMs for the future relative to the historical climate mean (non-standardized). TX and TN are presented as absolute anomalies $\left({ }^{\circ} \mathrm{C}\right)$, while PR is displayed as percentage anomalies (\%). Box plots of anomalies for the most relevant predictors are displayed.

Received: 13 January 2021; Accepted: 16 July 2021

Published online: 29 July 2021

\section{References}

1. Bindi, M. \& Olesen, J. E. The responses of agriculture in Europe to climate change. Reg. Environ. Change 11, 151-158 (2011).

2. Müller, C., Cramer, W., Hare, W. L. \& Lotze-Campen, H. Climate change risks for African agriculture. Proc. Natl. Acad. Sci. USA 108, 4313-4315 (2011)

3. Beach, R. H. et al. Climate change impacts on US agriculture and forestry: Benefits of global climate stabilization. Environ. Res. Lett. 10, 095004 (2015) 
4. Ray, D. K., Gerber, J. S., Macdonald, G. K. \& West, P. C. Climate variation explains a third of global crop yield variability. Nat. Commun. 6, 5989 (2015).

5. Schlenker, W. \& Roberts, M. J. Nonlinear temperature effects indicate severe damages to U.S. crop yields under climate change. Proc. Natl. Acad. Sci. USA 106, 15594-15598 (2009).

6. Ciscar, J. C., Fisher-Vanden, K. \& Lobell, D. B. Synthesis and review: An inter-method comparison of climate change impacts on agriculture. Environ. Res. Lett. 13, 070401 (2018).

7. Van Meijl, H. et al. Comparing impacts of climate change and mitigation on global agriculture by 2050. Environ. Res. Lett. 13, 064021 (2018).

8. Tubiello, F. N. et al. The FAOSTAT database of greenhouse gas emissions from agriculture. Environ. Res. Lett. 8, 15009-15019 (2013).

9. Frank, S. et al. Reducing greenhouse gas emissions in agriculture without compromising food security?. Environ. Res. Lett. 12, 105004 (2017).

10. Ignaciuk, A. \& Mason-D'Croz, D. Modelling Adaptation to climate change in agriculture. (2014). https://doi.org/10.1787/5jxrclljnb xq-en.

11. Martinich, J., Crimmins, A., Beach, R. H., Thomson, A. \& McFarland, J. Focus on agriculture and forestry benefits of reducing climate change impacts. Environ. Res. Lett. 12, 060301 (2017).

12. Van Grinsven, H. J. M., Erisman, J. W., De Vries, W. \& Westhoek, H. Potential of extensification of European agriculture for a more sustainable food system, focusing on nitrogen. Environ. Res. Lett. 10, 025002 (2015).

13. Agovino, M., Casaccia, M., Ciommi, M., Ferrara, M. \& Marchesano, K. Agriculture, climate change and sustainability: The case of EU-28. Ecol. Indic. 105, 525-543 (2019).

14. Jones, B. \& O’Neill, B. C. Spatially explicit global population scenarios consistent with the Shared Socioeconomic Pathways. Environ. Res. Lett. 11, 084003 (2016).

15. Branca, G., Lipper, L., McCarthy, N. \& Jolejole, M. C. Food security, climate change, and sustainable land management. A review. Agron. Sustain. Dev. 33, 635-650 (2013).

16. Wheeler, T. \& Von Braun, J. Climate change impacts on global food security. Science 341, 508-513 (2013).

17. Zampieri, M. et al. Adaptation and sustainability of water management for rice agriculture in temperate regions: The Italian casestudy. L. Degrad. Dev. 30, 2033-2047 (2019).

18. Shewry, P. R. Wheat. J. Exp. Bot. 60, 1537-1553 (2009).

19. Diffenbaugh, N. S. \& Giorgi, F. Climate change hotspots in the CMIP5 global climate model ensemble. Clim. Change 114, 813-822 (2012).

20. Alessandri, A. et al. Robust assessment of the expansion and retreat of Mediterranean climate in the 21st century. Sci. Rep. 4, 1-8 (2014).

21. Trenberth, K. E. Changes in precipitation with climate change. Clim. Res. 47, 123-138 (2011).

22. Giorgi, F., Jones, C. \& Asrar, G. Addressing climate information needs at the regional level: The CORDEX framework. WMO Bull. (2009).

23. Jacob, D. et al. Regional climate downscaling over Europe: perspectives from the EURO-CORDEX community. Reg. Environ. Change 20, 1-20 (2020).

24. Soares, P. M. M., Cardoso, R. M., Ferreira, J. J. \& Miranda, P. M. A. Climate change and the Portuguese precipitation: ENSEMBLES regional climate models results. Clim. Dyn. 45, 1771-1787 (2015).

25. Soares, P. M. M., Cardoso, R. M., Lima, D. C. A. \& Miranda, P. M. A. Future precipitation in Portugal: High-resolution projections using WRF model and EURO-CORDEX multi-model ensembles. Clim. Dyn. 49, 2503-2530 (2017).

26. Jacob, D. et al. EURO-CORDEX: New high-resolution climate change projections for European impact research. Reg. Environ. Change 14, 563-578 (2014).

27. Prein, A. F. et al. Precipitation in the EURO-CORDEX $0.11^{\circ}$ and $0.44^{\circ}$ simulations: High resolution, high benefits? Clim. Dyn. 46, 383-412 (2016).

28. Cardoso, R. M., Soares, P. M. M., Lima, D. C. A. \& Miranda, P. M. A. Mean and extreme temperatures in a warming climate: EURO CORDEX and WRF regional climate high-resolution projections for Portugal. Clim. Dyn. 52, 129-157 (2019).

29. Vautard, R. et al. The simulation of European heat waves from an ensemble of regional climate models within the EURO-CORDEX project. Clim. Dyn. 41, 2555-2575 (2013).

30. Choubin, B., Khalighi-Sigaroodi, S., Malekian, A. \& Kişi, Ö. Multiple linear regression, multi-layer perceptron network and adaptive neuro-fuzzy inference system for forecasting precipitation based on large-scale climate signals. Hydrol. Sci. J. 61, 1001-1009 (2016).

31. Cannon, A. J. \& McKendry, I. G. A graphical sensitivity analysis for statistical climate models: Application to Indian monsoon rainfall prediction by artificial neural networks and multiple linear regression models. Int. J. Climatol. 22, 1687-1708 (2002).

32. Hsiang, S. M., Meng, K. C. \& Cane, M. A. Civil conflicts are associated with the global climate. Nature 476, 438-441 (2011).

33. Wilks, D. S. Statistical Methods in the Atmospheric Sciences. (Elsevier/Academic Press, 2011).

34. Gouveia, C., Liberato, M. L. R., DaCamara, C. C., Trigo, R. M. \& A.Ramos, M. Modelling past and future wine production in the Portuguese Douro Valley. Clim. Res. 48, 349-362 (2011).

35. Ribeiro, A. F. S., Russo, A., Gouveia, C. M. \& Páscoa, P. Modelling drought-related yield losses in Iberia using remote sensing and multiscalar indices. Theoretical and Applied Climatology 1-18 (2018). https://doi.org/10.1007/s00704-018-2478-5 (2018).

36. Pavlova, V. et al. Future changes in spring wheat yield in the European Russia as inferred from a large ensemble of high-resolution climate projections. Environ. Res. Lett. 14, 034010 (2019).

37. Qian, B., De Jong, R., Huffman, T., Wang, H. \& Yang, J. Projecting yield changes of spring wheat under future climate scenarios on the Canadian Prairies. Theor. Appl. Climatol. 123, 651-669 (2016).

38. Clarke, D., Hess, T. M., Haro-Monteagudo, D., Semenov, M. A. \& Knox, J. W. Assessing future drought risks and wheat yield losses in England. Agric. For. Meteorol. 108248. https://doi.org/10.1016/j.agrformet.2020.108248 (2020).

39. Dubey, S. K. \& Sharma, D. Assessment of climate change impact on yield of major crops in the Banas River Basin, India. Sci. Total Environ. 635, 10-19 (2018).

40. Gammans, M., Mérel, P. \& Ortiz-Bobea, A. Negative impacts of climate change on cereal yields: Statistical evidence from France. Environ. Res. Lett. 12, 054007 (2017).

41. Yang, C., Fraga, H., van Ieperen, W., Trindade, H. \& Santos, J. A. Effects of climate change and adaptation options on winter wheat yield under rainfed Mediterranean conditions in southern Portugal. Clim. Change 154, 159-178 (2019).

42. Hernández-Barrera, S. \& Rodríguez-Puebla, C. Wheat yield in Spain and associated solar radiation patterns. Int. J. Climatol. 37, 45-58 (2017).

43. Iglesias, A., Rosenzweig, C. \& Pereira, D. Agricultural impacts of climate change in Spain: Developing tools for a spatial analysis. Glob. Environ. Change 10, 69-80 (2000).

44. Ruiz-Ramos, M. \& Mínguez, M. I. Evaluating uncertainty in climate change impacts on crop productivity in the Iberian Peninsula. Clim. Res. 44, 69-82 (2010).

45. Fraga, H., Pinto, J. G., Viola, F. \& Santos, J. A. Climate change projections for olive yields in the Mediterranean Basin. Int. J. Climatol. 40, 769-781 (2020). 
46. Paredes, P., de Melo-Abreu, J. P., Alves, I. \& Pereira, L. S. Assessing the performance of the FAO AquaCrop model to estimate maize yields and water use under full and deficit irrigation with focus on model parameterization. Agric. Water Manag. 144, 81-97 (2014).

47. Ruiz-Ramos, M., Sánchez, E., Gallardo, C. \& Mínguez, M. I. Impacts of projected maximum temperature extremes for C21 by an ensemble of regional climate models on cereal cropping systems in the Iberian Peninsula. Nat. Hazards Earth Syst. Sci. 11, 3275-3291 (2011).

48. Ruiz-Ramos, M. et al. Adaptation response surfaces for managing wheat under perturbed climate and $\mathrm{CO}_{2}$ in a Mediterranean environment. Agric. Syst. 159, 260-274 (2018).

49. Hernandez-Barrera, S., Rodriguez-Puebla, C. \& Challinor, A. J. Effects of diurnal temperature range and drought on wheat yield in Spain. Theor. Appl. Climatol. 129, 503-519 (2017).

50. van Vuuren, D. P. et al. The representative concentration pathways: An overview. Clim. Change 109, 5-31 (2011).

51. Ferrise, R., Moriondo, M. \& Bindi, M. Probabilistic assessments of climate change impacts on durum wheat in the Mediterranean region. Nat. Hazards Earth Syst. Sci. 11, 1293-1302 (2011).

52. Lobell, D. B. \& Asseng, S. Comparing estimates of climate change impacts from process-based and statistical crop models. Environ. Res. Lett. 12, 15001 (2017).

53. Gouveia, C. \& Trigo, R. M. Influence of climate variability on wheat production in Portugal. In geoENV VI-Geostatistics for Environmental Applications 335-345 (Springer Netherlands, 2008). https://doi.org/10.1007/978-1-4020-6448-7_28.

54. Gouveia, C. \& Trigo, R. M. The impacts of the NAO on the vegetation activity in Iberia. In Advances in Global Change Research 46, 113-128 (Springer International Publishing, 2011).

55. Ortiz, R. et al. Climate change: Can wheat beat the heat?. Agric. Ecosyst. Environ. 126, 46-58 (2008).

56. Webber, H. et al. Diverging importance of drought stress for maize and winter wheat in Europe. Nat. Commun. 9, 1-10 (2018).

57. Porter, J. R. \& Gawith, M. Temperatures and the growth and development of wheat: A review. Eur. J. Agron. 10, 23-36 (1999).

58. Tao, F. et al. Why do crop models diverge substantially in climate impact projections? A comprehensive analysis based on eight barley crop models. Agric. For. Meteorol. 281, 107851 (2020).

59. Lobell, D. B. et al. The critical role of extreme heat for maize production in the United States. Nat. Clim. Change 3, 497-501 (2013).

60. Webber, H. et al. Physical robustness of canopy temperature models for crop heat stress simulation across environments and production conditions. Field Crop. Res. 216, 75-88 (2018).

61. Ribeiro, A. F. S., Russo, A., Gouveia, C. M. \& Páscoa, P. Copula-based agricultural drought risk of rainfed cropping systems. Agric. Water Manag. 223, 105689 (2019).

62. Ribeiro, A. F. S., Russo, A., Gouveia, C. M., Páscoa, P. \& Zscheischler, J. Risk of crop failure due to compound dry and hot extremes estimated with nested copulas. Biogeosciences 17, 4815-4830 (2020).

63. Austin, R. B., Playán, E. \& Gimeno, J. Water storage in soils during the fallow: Prediction of the effects of rainfall pattern and soil conditions in the Ebro valley of Spain. Agric. Water Manag. 36, 213-231 (1998).

64. Carvalho, P., Azam-Ali, S. \& Foulkes, M. J. Quantifying relationships between rooting traits and water uptake under drought in Mediterranean barley and durum wheat. J. Integr. Plant Biol. 56, 455-469 (2014).

65. Cossani, C. M., Slafer, G. A. \& Savin, R. Yield and biomass in wheat and barley under a range of conditions in a Mediterranean site. Field Crop. Res. 112, 205-213 (2009).

66. Peña-Gallardo, M., Vicente-Serrano, S. M., Domínguez-Castro, F. \& Beguería, S. The impact of drought on the productivity of two rainfed crops in Spain. Nat. Hazards Earth Syst. Sci. 19, 1215-1234 (2019).

67. Zampieri, M., Ceglar, A., Dentener, F. \& Toreti, A. Wheat yield loss attributable to heat waves, drought and water excess at the global, national and subnational scales. Environ. Res. Lett. 12, 064008 (2017).

68. Zampieri, M. et al. Climate resilience of the top ten wheat producers in the Mediterranean and the Middle East. Reg. Environ. Change 20, 1-9 (2020).

69. Zampieri, M. et al. When will current climate extremes affecting maize production become the norm?. Earth's Futur. 7, 113-122 (2019).

70. FAO. Adaptation to Climate Change in Agriculture, Forestry and Fisheries: Perspective Framework and Priorities. (2011).

71. Lopes, M. S. et al. Exploiting genetic diversity from landraces in wheat breeding for adaptation to climate change. J. Exp. Bot. 66, 3477-3486 (2015).

72. Mansour, E., Moustafa, E. S. A., El-Naggar, N. Z. A., Abdelsalam, A. \& Igartua, E. Grain yield stability of high-yielding barley genotypes under Egyptian conditions for enhancing resilience to climate change. Crop Pasture Sci. 69, 681-690 (2018).

73. Liu, K. et al. Identifying optimal sowing and flowering periods for barley in Australia: A modelling approach. Agric. For. Meteorol. 282-283, 107871 (2020).

74. Hunt, J. R. et al. Early sowing systems can boost Australian wheat yields despite recent climate change. Nat. Clim. Change 9, 244-247 (2019).

75. Semenov, M. A., Stratonovitch, P., Alghabari, F. \& Gooding, M. J. Adapting wheat in Europe for climate change. J. Cereal Sci. 59, 245-256 (2014).

76. Kothari, K. et al. Potential climate change adaptation strategies for winter wheat production in the Texas High Plains. Agric. Water Manag. 225, 105764 (2019).

77. Reynolds, M. et al. Exploring genetic resources to increase adaptation of wheat to climate change. In Advances in Wheat Genetics: From Genome to Field 355-368 (Springer Japan, 2015). https://doi.org/10.1007/978-4-431-55675-6_41.

78. Iglesias, A. \& Minguez, M. I. Modelling crop-climate interactions in Spain: Vulnerability and adaptation of different agricultural systems to climate change. Mitig. Adapt. Strateg. Glob. Change 1, 273-288 (1997).

79. Luo, Q., Bellotti, W., Williams, M. \& Wang, E. Adaptation to climate change of wheat growing in South Australia: Analysis of management and breeding strategies. Agric. Ecosyst. Environ. 129, 261-267 (2009).

80. Mondal, S. et al. Earliness in wheat: A key to adaptation under terminal and continual high temperature stress in South Asia. Field Crop. Res. 151, 19-26 (2013).

81. Meza, F. J., Silva, D. \& Vigil, H. Climate change impacts on irrigated maize in Mediterranean climates: Evaluation of double cropping as an emerging adaptation alternative. Agric. Syst. 98, 21-30 (2008).

82. Xu, J. et al. Double cropping and cropland expansion boost grain production in Brazil. Nat. Food 2, 264-273 (2021).

83. Semenov, M. A. \& Halford, N. G. Identifying target traits and molecular mechanisms for wheat breeding under a changing climate. J. Exp. Bot. 60, 2791-2804 (2009).

84. Wang, Z. biao, Chen, J., Tong, W. jie, Xu, C. chun \& Chen, F. Impacts of climate change and varietal replacement on winter wheat phenology in the North China Plain. Int. J. Plant Prod. 12, 251-263 (2018).

85. Asseng, S. et al. Uncertainty in simulating wheat yields under climate change. Nat. Clim. Change 3, 827-832 (2013).

86. Estes, L. D. et al. Comparing mechanistic and empirical model projections of crop suitability and productivity: Implications for ecological forecasting. Glob. Ecol. Biogeogr. 22, 1007-1018 (2013).

87. Ceglar, A., Zampieri, M., Toreti, A. \& Dentener, F. Observed northward migration of agro-climate zones in europe will further accelerate under climate change. Earth's Future 7, 1088-1101 (2019).

88. Russo, A. et al. Assessing the role of drought events on wildfires in the Iberian Peninsula. Agric. For. Meteorol. 237-238, 50-59 (2017). 
89. Dee, D. P. et al. The ERA-Interim reanalysis: Configuration and performance of the data assimilation system. Q. J. R. Meteorol. Soc. 137, 553-597 (2011).

90. Rockel, B., Will, A. \& Hense, A. The regional climate model COSMO-CLM (CCLM). Meteorol. Z. 17, 347-348 (2008).

91. Nabat, P. et al. Modulation of radiative aerosols effects by atmospheric circulation over the Euro-Mediterranean region. Atmos. Chem. Phys. 20, 8315-8349 (2020).

92. Christensen, O. B. et al. The HIRHAM Regional Climate Model Version 5 (beta). (2007).

93. Skamarock, W. C. et al. A description of the Advanced Research WRF Version 3, NCAR Technical Note TN-475+STR. Technical Report (2008).

94. Van Meijgaard, E. et al. The KNMI Regional Atmospheric Climate Model RACMO Version 2.1. (2008).

95. Jacob, D. et al. A comprehensive model inter-comparison study investigating the water budget during the BALTEX-PIDCAP period. Meteorol. Atmos. Phys. 77, 19-43 (2001).

96. Samuelsson, P. et al. The Rossby Centre Regional Climate model RCA3: Model description and performance. Tellus Ser. A Dyn. Meteorol. Oceanogr. 63, 4-23 (2011).

\section{Acknowledgements}

This work was supported by national funds through FCT (Fundação para a Ciência e a Tecnologia, Portugal) under Project IMPECAF-PTDC/CTA-CLI/28902/2017 (V.B., A.R., C.G., P.S.), Project LEADING-PTDC/ CTA-MET/28914/2017 (R.C., P.S.), and Project UIDB/50019/2020-IDL. A.F.S.R. acknowledges funding from the Swiss National Science Foundation (Project Number 186282). We further thank the editor for the constructive and valuable comments and suggestions that helped improve the manuscript. Finally, all authors are grateful to the World Climate Research Program Working Group on Regional Climate and the Working Group on Coupled Modelling, the former coordinating body of CORDEX and responsible panel for CMIP5. The authors also thank the climate modelling groups (listed in Table 1 of this paper) for producing and making available their EUROCORDEX model output in the Portal Earth System Grid Federation.

\section{Author contributions}

V.B., A.F.S.R, A.R. and C.G conceived the study. V.B. performed the analysis of the results with the contribution of all authors. A.F.S.R. provided agricultural datasets and R.C. and P.S. provided climate datasets. V.B. wrote the manuscript and all authors provided comments and feedback.

\section{Competing interests}

The authors declare no competing interests.

\section{Additional information \\ Supplementary Information The online version contains supplementary material available at https://doi.org/ 10.1038/s41598-021-95014-6.}

Correspondence and requests for materials should be addressed to V.A.B.

Reprints and permissions information is available at www.nature.com/reprints.

Publisher's note Springer Nature remains neutral with regard to jurisdictional claims in published maps and institutional affiliations.

(c) (i) Open Access This article is licensed under a Creative Commons Attribution 4.0 International License, which permits use, sharing, adaptation, distribution and reproduction in any medium or format, as long as you give appropriate credit to the original author(s) and the source, provide a link to the Creative Commons licence, and indicate if changes were made. The images or other third party material in this article are included in the article's Creative Commons licence, unless indicated otherwise in a credit line to the material. If material is not included in the article's Creative Commons licence and your intended use is not permitted by statutory regulation or exceeds the permitted use, you will need to obtain permission directly from the copyright holder. To view a copy of this licence, visit http://creativecommons.org/licenses/by/4.0/.

(C) The Author(s) 2021 